\title{
Evidence for the essential role of Helicobacter pylori in gastric ulcer disease
}

\author{
J Labenz, G Börsch
}

\begin{abstract}
Helicobacter pylori (H pylori) eradication heals chronic active type $B$ gastritis and dramatically changes the natural history of duodenal ulcer disease. There are few data concerning the role of anti-H pylori treatment in gastric ulcer disease. A total of 83 patients presenting with $H$ pylori positive active gastric ulcer disease were treated with omeprazole and antibiotics (amoxicillin, ciprofloxacin, roxithromycin) in seven different clinical protocols, each of which included the attempt to eradicate $\boldsymbol{H}$ pylori infection and to evaluate the post-therapeutic course of ulcer disease. The overall proportion of $\boldsymbol{H}$ pylori eradication was $67.9 \%$ (53 of 78 patients available for follow up). Best results were obtained with two week treatment regimens comprising omeprazole $20 \mathrm{mg}$ twice daily and amoxicillin $500 \mathrm{mg}$ four times a day or $1000 \mathrm{mg}$ twice daily (eradication $>80 \%$ ). Eradication of $\boldsymbol{H}$ pylori speeds up ulcer healing, with a six week healing rate of $84.9 \%$ compared with $60 \%$ in patients with persistent $H$ pylori infection $(p=0 \cdot 0148)$. In a subgroup of 11 patients with refractory ulcers, $H$ pylori eradication $(n=10)$ was associated with ulcer healing on continued acid suppression in nine cases. One male patient with chronic antral ulcer did not respond to treatment within the next six months ( $H$ pylori and ulcer persistence), and in one female patient a resistent body ulcer was identified as gastric lymphoma. Fifty patients with healed ulcers were followed up for one year. Patients with $(n=32)$ and without $(n=18)$ bacterial eradication had similar demographic and clinical characteristics. $H$ pylori eradication was associated with a statistically significant reduction of ulcer recurrences (3.1 $v$ $55.6 \%, p<0.001)$. This study concludes that $H$ pylori eradication considerably changes the natural history of $\boldsymbol{H}$ pylori associated gastric ulcer disease. In addition, $H$ pylori eradication speeds up ulcer healing and is associated with healing of previously refractory ulcers. Thus, treatment aimed at bacterial eradication should be considered in all patients with gastric ulcers severe enough to contemplate further treatment options.

(Gut 1994; 35: 19-22)
\end{abstract}

Department of Medisabeth-Hospital, Academic Teaching Hospital of the University of Essen, Germany $J$ Labenz

G Börsch

Correspondence to: Dr J Labenz, Department of Medicine, Elisabeth-Hospital, Moltkestr 61, 45138 Essen, Germany.

Accepted for publication 12 May 1993
The dramatic effect of eradicating Helicobac pylori ( $H$ pylori) on the medium term natural course of duodenal ulcer disease is sufficiently well reported by now. ${ }^{1-4}$ Therefore, $H$ pylori treatment is recommended for patients with relapsing duodenal ulcer disease. ${ }^{5}$ In contrast, there is still a considerable dearth of knowledge on the post-therapeutic course of gastric ulcer disease. In 1992, a first controlled study showed that $H$ pylori positive gastric ulcer disease will respond in exactly the same way as duodenal ulcer disease does. ${ }^{2}$ To shed further light on this issue, we report our short and medium term experience in patients with $H$ pylori associated gastric ulcers treated with omeprazole and antibiotics.

\section{Methods}

In the past three years, a total of 83 patients presenting with $H$ pylori positive (proved by culture or histological examination, or both) active gastric ulcer disease participated in seven different, not randomised and uncontrolled clinical protocols, each of which included the attempt to eradicate $H$ pylori. The studies were designed to evaluate the $H$ pylori eradication potency of the various regimens and the posttherapeutic course of ulcer disease. A refractory ulcer was defined as an ulcer that did not heal within three months on conventional treatment with full dose $\mathrm{H}_{2}$ blockers or $20 \mathrm{mg}$ omeprazole.

Five patients missed the first follow up investigation. The remaining 78 patients (Table I) were treated with either omeprazole ( $40 \mathrm{mg}$ every morning) and ciprofloxacin (500 mg twice daily) for one week $(n=11)$, omeprazole $(40 \mathrm{mg}$ every morning) and amoxicillin (500 mg four times daily) for one week $(n=8)$, omeprazole $(40 \mathrm{mg}$ twice daily) and amoxicillin (500 $\mathrm{mg}$ four times daily) for one week $(n=12)$, omeprazole $(20 \mathrm{mg}$ twice daily) and amoxicillin (500 mg four times daily) for two weeks ( $n=20)$, omeprazole ( $20 \mathrm{mg}$ twice daily) day 1-14 and amoxicillin (500 mg four times daily) day 8-14 $(n=9)$, omeprazole (20 mg twice daily) and amoxicillin (1 $\mathrm{g}$ twice daily) for two weeks $(n=15)$ or with omeprazole $(2 \times 20$ $\mathrm{mg}$ twice daily) and roxithromycin (300 $\mathrm{mg}$ twice daily) for two weeks $(n=3)$. After the study period of treatment had ended, patients were treated with $300 \mathrm{mg}$ ranitidine in the evening $(n=70)$ or $20 \mathrm{mg}$ omeprazole $(n=8)$ up to the six week follow up investigation. In patients with incomplete ulcer healing at that time $(n=18)$ treatment was continued with $20 \mathrm{mg}$ omeprazole every morning until complete ulcer healing proved by endoscopy was achieved.

Patients routinely had an endoscopy before treatment and after six weeks. Patients with incomplete ulcer healing after six weeks were reinvestigated by endoscopy at four week intervals. During the follow up without any anti-ulcer treatment, patients were instructed to report to the study physicians with all symptoms related to their gastric ulcer disease, who suggested and performed repeat endoscopies. All endoscopically proved ulcer relapses were then registered. Beside these 'on demand' visits and endoscopies, 
TABLE I Demographic and clinical characteristics of the study patients (total group; subgroups with regard to the treatment regimens: group I: one week ciprofloxacin $500 \mathrm{mg}$ twice daily plus omeprazol $40 \mathrm{mg}$ every morning; group II-VI: amoxicillin $500 \mathrm{mg}$ four times daily for one week (II, III), two weeks (IV), day 8-14(V) or $1 \mathrm{~g}$ twice daily two weeks (VI) plus omeprazole $40 \mathrm{mg}$ every morning (II), $40 \mathrm{mg}$ twice daily (III), $20 \mathrm{mg}$ twice daily (IV-VI); group VIII: roxithromycin $300 \mathrm{mg}$ twice daily plus omeprazole 20 mg twice daily)

\begin{tabular}{|c|c|c|c|c|c|c|c|c|}
\hline & $\begin{array}{l}\text { Total group } \\
(n=78)\end{array}$ & $\begin{array}{l}\text { Group } I \\
(n=I I)\end{array}$ & $\begin{array}{l}\text { Group } I I \\
(n=8)\end{array}$ & $\begin{array}{l}\text { Group } I I I \\
(n=I 2)\end{array}$ & $\begin{array}{l}\text { Group IV } \\
(n=20)\end{array}$ & $\underset{(n=9)}{\text { Group } V}$ & $\begin{array}{l}\text { Group VI } \\
(n=15)\end{array}$ & $\underset{(n=3)}{\text { Group }}$ VII \\
\hline Median age (y) (range) & $65 \cdot 5(29-86)$ & $53(39-82)$ & $66 \cdot 5(46-86)$ & $64(44-82)$ & $59(35-83)$ & $67(52-78)$ & $69(29-86)$ & $80(74-86)$ \\
\hline $\operatorname{Men} /$ women $(\mathrm{n})$ & $44 / 34$ & $6 / 5$ & $3 / 5$ & $9 / 3$ & $14 / 6$ & $3 / 6$ & $8 / 7$ & $1 / 2$ \\
\hline Ulcer history (n) & 55 & 7 & 6 & 10 & 14 & 5 & 12 & 1 \\
\hline First ulcer (n) & 23 & 4 & 2 & 2 & 6 & 4 & 3 & 2 \\
\hline Aspirin or NSAID use $(n)^{\star}$ & 16 & 3 & 1 & 2 & 4 & 2 & 2 & 2 \\
\hline Smoker (n) & 35 & 7 & 3 & 4 & 9 & 3 & 8 & l \\
\hline \multicolumn{9}{|l|}{ Ulcer location: } \\
\hline Antral ulcer (n) & 55 & 9 & 5 & 10 & 14 & 6 & 9 & 2 \\
\hline Body ulcer (n) & 21 & 2 & 3 & 2 & 6 & 3 & 4 & 1 \\
\hline Antral+body ulcer (n) & 21 & 0 & 0 & 0 & 0 & 0 & 2 & 0 \\
\hline
\end{tabular}

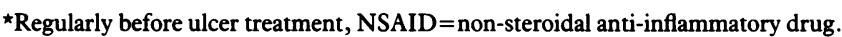

a routine clinical examination and an upper gastrointestinal endoscopy were performed in 50 patients (Table II) after one year.

During each endoscopy, four antrum and four body biopsy specimens were taken and analysed for $H$ pylori colonisation by an urease test, microscopy of a methylene blue stained mucosal smear, specific culture, and histological tests after modified Giemsa stain as described elsewhere ${ }^{67}$ Eradication was defined as inability to show $H$ pylori four weeks or more after discontinuation of study treatment by all four tests.

The age distribution of the 50 patients followed up over one year was statistically compared with the Wilcoxon rank sum test. All categorial data were statistically compared with the $\chi^{2}$ test or with Fisher's exact test, when appropriate. All statistical calculations were two tailed. Differences were considered significant at a $5 \%$ probability value.

\section{Results}

Eighty three patients with $H$ pylori positive gastric ulcers entered the study. Five patients were lost to follow up. Before treatment, $H$ pylori colonisation of the gastric mucosa was detected by urease test in all patients, histologically in 82 , microscopically after methylene blue staining in 74 , and by culture in 67 patients.

The overall proportion of $H$ pylori eradication was $67.9 \%$ ( 53 of 78 patients). In patients treated with amoxicillin plus omeprazole, there was a trend (without statistical significance) towards better $H$ pylori eradication rates after a two week antibiotic course compared with one week amoxicillin treatment $(85.7 v 69 \%, \mathrm{p}>0.05)$ and in patients with body ulcers compared with those

TABLE II Demographic and clinical characteristics of 50 patients with gastric ulcer disease prospectively followed up for one year with regard to their Helicobacter pylori (HP) state after treatment

\begin{tabular}{llll}
\hline & $\begin{array}{l}\text { HP negative } \\
(n=32)\end{array}$ & $\begin{array}{l}\text { HP positive } \\
(n=18)\end{array}$ & $p$ \\
\hline Median age (y)(range) & $65 \cdot 5(49-87)$ & $68(36-82)$ & NS \\
Men/women (n) & $19 / 13$ & $10 / 8$ & NS \\
Asprin or NSAID use (n) & 2 & 0 & NS \\
Location of index ulcer: & 24 & 13 & NS \\
$\quad \begin{array}{l}\text { Antral ulcer (n) } \\
\text { Body ulcer (n) }\end{array}$ & 8 & 5 & NS \\
\hline
\end{tabular}

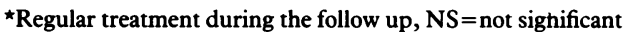
( $>0.05) ;$ NSAID = non-steroidal anti-inflammatory drug. who had antral manifestation of their ulcer disease $(94.4 v 72 \cdot 7 \%, \mathrm{p}>0.05)$. Ciprofloxacin was obviously ineffective as dual treatment with omeprazole (eradication rate $18 \cdot 2 \%$ (2/11 patients)). The group of patients treated with roxithromycin in addition to omeprazole $(n=3)$ was too small for a meaningful subgroup analysis of the eradication potency.

Six weeks after the beginning of the study treatment, complete ulcer healing was endoscopically seen in 60 of 78 patients $(76.9 \%)$. Healing was significantly achieved more frequently in patients with successful $H$ pylori eradication (84.9 (45/53 patients) $v 60 \%(15 / 25$ patients), $p=0.0148$, Table III) despite similar distributions of ulcer size in these two group (median ulcer size: $11.5 \mathrm{~mm} v 12 \mathrm{~mm}$ ).

The total study group comprised 11 patients with $H$ pylori positive refractory gastric ulcers (six men, five women, median age 53 years, median pretreatment with $\mathrm{H}_{2}$ blockers $(\mathrm{n}=9)$ or omeprazole $(n=2)$ six months (range: $3->12$ months)) who were treated with an omeprazole plus amoxicillin regimen. After eradication of $H$ pylori $(\mathrm{n}=10)$ from the gastric mucosa eight ulcers healed within the next $\operatorname{six}(n=6)$ to 10 weeks $(n=2)$. A giant prepyloric ulcer (diameter $5 \mathrm{~cm}$ ) was completely epithelised after five months. In one female patient, the body ulcer

TABLE III Six week ulcer healing rates with regard to the Helicobacter pylori (HP) state after treatment (total study group: $n=78$ patients

\begin{tabular}{lll}
\hline & HP eradication & $\begin{array}{l}\text { HP persistence } \\
(n)\end{array}$ \\
\hline Ulcer healing after 6 weeks $(\mathrm{n})$ & 45 & 15 \\
Residual ulcer after 6 weeks $(\mathrm{n})$ & 8 & 10 \\
\hline & $45 / 53(84 \cdot 9 \%)^{\star}$ & $15 / 25(60 \%)$ \\
\hline
\end{tabular}

${ }^{\star} \mathrm{p}=0.0148\left(\chi^{2}\right.$ test $)$

TABLE IV Medium term clinical course of gastric ulcer disease with regard to the Helicobacter pylori (HP) state after treatment (patients data are listed in Table II)

\begin{tabular}{|c|c|c|c|}
\hline & $\begin{array}{l}\text { HP negative } \\
(n=32)\end{array}$ & $\begin{array}{l}\text { HP positive } \\
(n=18)\end{array}$ & $p$ \\
\hline $\begin{array}{l}\text { Follow up (months) } \\
H \text { pylori reinfection (n) } \\
\text { Ulcer relapse (n) }\end{array}$ & $\begin{array}{l}12 \\
2 \\
1(3 \cdot 1 \%)^{\star}\end{array}$ & $\frac{12}{10}(55 \cdot 6 \%)$ & $<0.001$ \\
\hline
\end{tabular}

$\star$ Patient receiving non-steroidal anti-inflammatory drugs, but $H P$ negative. 
was later identified as a gastric lymphoma and surgical resection was done. In a 40 year male patient with persistent $H$ pylori colonisation of the gastric mucosa, a chronic antral ulcer did not heal during the follow up of six months.

We prospectively followed up 50 patients with healed ulcers for one year. $H$ pylori infection was eradicated in 32 patients and persisted in 18 patients. These two groups of patients had similar demographic and clinical characteristics (Table II). $H$ pylori infection was a strong predictor of ulcer recurrences. Within the follow up period 10 of 18 post-treatment $H$ pylori positive patients $(55.6 \%)$ and only one of 32 patients with $H$ pylori eradication $(3 \cdot 1 \%)$ had an endoscopically proved ulcer relapse $(\mathrm{p}<0.001$, Table IV). The ulcer recurrence after bacterial eradication was associated with diclofenac treatment. The $H$ pylori reinfection rate in the first year after eradication was $6 \cdot 25 \%$ (two of 32 patients).

\section{Discussion}

A very strong association of $H$ pylori infection of the gastric mucosa with chronic active type $\mathbf{B}$ gastritis and duodenal ulcer has been clearly established by now. The prevalence of $H$ pylori in gastric ulcer disease varies more widely, but has most consistently been found to be around $70 \%{ }^{8}$ After exclusion of patients with known causes of their ulcer disease, $H$ pylori infection has been detected with a much higher frequency of $96 \%$ in subgroups with idiopathic gastric ulcers, which is equivalent to the $H$ pylori prevalence in duodenal ulcer disease. ${ }^{9}$ A strong association, however, is not a proof of causation. Therefore, additional evidence clearly pointing to a causal relation between $H$ pylori infection and gastric ulcer disease has to be provided. A powerful argument for causation could be the effect of treatment interventions. Thus, elimination of the putative causal agent ( $H$ pylori) should prevent the illness (gastric ulcer).

Indeed, a truly dramatic change of the natural course of $H$ pylori associated gastric ulcer disease after bacterial eradication was shown by our study. In patients with $H$ pylori eradication, the one year ulcer relapse rate was one of 32 (3.1\%), while failure to eradicate $H$ pylori resulted in an endoscopically proved ulcer recurrence rate of 10 of 18 patients $(55.6 \%, \mathrm{p}<0.001)$. The one year re-infection rate determined by this study was $6 \cdot 25 \%$. These findings are in accordance with those reported by Graham et al, ${ }^{2}$ who randomly treated 26 patients with $H$ pylori positive gastric ulcers with either ranitidine alone or triple therapy plus ranitidine. The only factors in Graham's and our studies associated with ulcer recurrence were $H$ pylori infection and the use of non-steroidal anti-inflammatory drugs. Preliminary data of the German gastric ulcer study support these findings. ${ }^{10}$ Thus, in addition to duodenal ulcer disease, $H$ pylori eradication may also cure gastric ulcer disease. Therefore, it seems to be warranted that a treatment aimed at bacterial eradication should be considered in all patients with $H$ pylori associated gastric ulcer disease severe enough to contemplate further treatment options (for example, frequent ulcer relapses, ulcer complications).

In addition, our data clearly suggest that similar to duodenal ulcers" ${ }^{11}$ - eradication of $H$ pylori infection speeds up gastric ulcer healing, with a six week healing rate of about $85 \%$ as opposed to $60 \%$ in gastric ulcer patients with persistent $H$ pylori colonisation. Moreover, most of the previously refractory gastric ulcers heal within six to 10 weeks after eradicating $H$ pylori on continued acid suppression. Both findings lend additional support to the assumption that $H$ pylori plays an important, probably causative part in the pathogenesis of the formerly 'idiopathic' gastric ulcer disease.

Up to now, the 'how' of anti- $H$ pylori treatment is still a matter of debate. Bismuth salts and treatment by a single antibiotic fail to eradicate $H$ pylori in a noteworthy proportion, but combined treatment regimens comprising bismuth salts and two antibiotics (for example, metronidazole plus amoxicillin or tetracycline) eradicated $H$ pylor in most of the treated patients and is recommended as the treatment of first choice to eradicate $H$ pylori in duodenal ulcer disease. ${ }^{12}$ Patients treated with such an elaborate regimen, however, complained of considerable side effects, clearly endangering a sufficiently high compliance rate in routine clinical practice. Recent studies have suggested that omeprazole enhanced single antibiotic (for example, amoxicillin, clarithromycin) regimens combine a sufficient simplicity and low complications with high rates of bacterial eradication. ${ }^{13-15}$ In our hands, double dose omeprazole $(20 \mathrm{mg}$ twice daily) plus amoxicillin $2 \mathrm{~g}$ for two weeks is at least equally effective in eradicating $H$ pylor in gastric as it is in duodenal ulcer disease. Therefore, it seems to be justified to recommend amoxicillin/ omeprazole as the treatment of first choice to eradicate $H$ pylori in $H$ pylori related duodenal and gastric ulcer diseases. Triple therapy may then be reserved as 'second line' therapeutic option for patients with treatment failure of omeprazole plus antibiotics or with suspected penicillin hypersensitivity.

1 Bayerdörffer E, Mannes GA, Sommer A, Höchter W, Weingart J, Hatz R, et al. High dose omeprazole treatmen combined with amoxicillin eradicates Helicobacter pylori. Eur f Gastroenterol Hepatol 1992; 4: 697-702.

2 Graham DY, Lew GM, Klein PD, Evans DG, Evans DJ, Saeed ZA, et al. Effect of treatment of Helicobacter pylori infection on the long-term recurrence of gastric or duodenal infection on the long-term recurrence of

3 Marshall BJ, Goodwin CS, Warren JR, Murray R, Blincow D, Blackbourn SJ, et al. Prospective double-blind trial of duodenal ulcer relapse after eradication of Campylobacter pylori. Lancet 1988; ii: $1437-42$.

4 Rauws EAJ, Tytgat GNJ. Cure of duodenal ulcer associated with eradication of Helicobacter pylori. Lancet 1990; ii: 1233-5.

5 Tytgat GNJ, Axon ATR, Dixon MF, Graham DY, Lee A, Marshall BJ. Helicobacter pylori: causal agent in peptic ulcer disease? Working Party Report. World Congress of Gastroenterology: 26th-31st August 1990, Sydney, Australia. Oxford: Blackwell Scientific, 1990: 36-45.

6 Börsch G, Labenz J, Rehner M, Rühl GH, Gyenes E Nachweis von Helicobacter pylori. Münch Med Wschr 1990 132: 391-4.

7 Labenz J, Gyenes E, Rühl GH, Peitz U, Börsch G. Diagnosis of Helicobacter pylori colonization of gastric mucosa. A of Helicobacter pylori colonization of gastric mucosa. A
prospective comparative study of direct tests and validity of prospective comparative study of direct tests

8 Wyatt JI, Dixon MF. Chronic gastritis - a pathogenetic approach. F Pathol 1988; 154: 113-24.

9 Rauws EAJ, Langenberg W, Houthoff $\mathrm{HJ}$, Zanen HC, Tytgat GNJ. Campylobacter pyloridis-associated chronic active antral gastritis. A prospective study of its prevalence and the effect of antibacterial and antiulcer treatment. Gastroenterology 1988; 94: 33-40. 
10 Bayerdörffer E, Mannes GA, Höchter W, Weingart J, Sommer A, Klann $\mathrm{H}$, et al. Antibacterial treatment of gastric ulcers. German gastric ulcer study. Ir $\mathcal{F}$ Med Sci 1992; 161 (suppl 10): 30.

11 Graham DY, Lew GM, Evans DG, Evans DJ, Klein PD. Effect of triple therapy (antibiotics plus bismuth) on duodenal ulcer healing. Ann Intern Med 1991; 115: 166-9.

12 Börsch GMA, Graham DY. Helicobacter pylori. In: Benjamin SB, Collen MJ, eds. Handbook of experimental pharmacology. Vol 99. Pharmacology of peptic ulcer disease. Berlin: Springer,
1991: 107-47.

13 Labenz J, Gyenes E, Rühl GH, Börsch G. Efficacy of omeprazole and amoxicillin to eradicate HP. Am $\mathcal{F}$ Gastroenterol 1992; 87: 1271

14 Labenz J, Gyenes E, Rühl GH, Börsch G. Amoxicillin plus omeprazole versus triple therapy for eradication of Helicobacter pylori in duodenal ulcer disease. Gut (In press).

15 Logan RPH, Gummett PA, Hegarty BT, Walker MM, Baron $\mathrm{JH}$, Misiewicz JJ. Clarithromycin and omeprazole for JH, Misiewicz JJ. Clarithromycin and
Helicobacter pylori. Lancet 1992; 340: 239. 